Check for updates

London

Cite this as: BMJ2021;374:n2289 http://dx.doi.org/10.1136/bmj.n2289 Published: 17 September 2021

\title{
Patients in England rate emergency services highly but pressures and staff shortages affect some aspects of care, finds survey
}

Matthew Limb

The Royal College of Emergency Medicine says staff shortages are to blame for many of the shortcomings in urgent and emergency care identified by patients in a major new survey. ${ }^{1}$

The survey of more than 48 ooo patients in 126 acute hospital trusts in England by the Care Quality Commission (CQC) was carried out in September 2020, during the pandemic, and reports experiences of attending a major consultant-led emergency department (type 1) or an urgent treatment centre or minor injury unit (type 3).

Ted Baker, the CQC's chief inspector of hospitals, said, "This year's survey shows some encouraging improvements with trust and confidence in clinicians, perceptions of cleanliness, and overall experience all performing better than in previous years."

Most patients said they were treated with respect and dignity and were given enough privacy when treated and examined. The proportion of patients who rated their overall experience as " 10 out of 10 " increased from $27 \%$ in 2016 and $29 \%$ in 2018 to $33 \%$ in 2020 for type 1 services, and from $33 \%$ in 2016 and $37 \%$ in 2018 to $44 \%$ for type 3 services.

But people were less positive about help with pain management, emotional support, the ability to be involved in their care, and with information provided at discharge to assist their care at home. While they were waiting to be treated or examined, almost half of patients using type 1 units (45\%) who reported that they needed help said that they were unable to get help with their condition or symptoms from a member of staff.

Katherine Henderson, president of the Royal College of Emergency Medicine, said that emergency medicine staff had worked exceptionally hard to deliver improvements but they were stretched too thinly. "Many of the areas that are a source of frustration for patients are largely a result of staff shortages and the existing workforce's ability to dedicate ample time to each patient," she said.

To meet current demand the NHS needs 2500 more consultants and 4000 nurses in urgent care departments in England, she said.

The survey also found younger people, women, people who reported a mental health condition, people whose attendance lasted more than four hours, and people who had recently visited a type 1 service "consistently reported poorer experiences of type 1 services,," said the CQC. Similarly, younger people and those whose attendance lasted more than four hours reported poorer experiences of type 3 services.
On interactions with staff, $81 \%$ and $87 \%$ of those who used type 1 and type 3 services, respectively, said they were treated with dignity and respect "all of the time.” Perceptions of cleanliness in units rose significantly (11\% up on 2018 survey results), most likely reflecting enhanced infection prevention and control measures.

The survey was conducted at a time when concerns about covid saw a significant reduction in patients seeking urgent and emergency care.

Type 3 attendances-the service where people were most likely to report their experience as being "very good"-were down 28\% from the last survey in 2018 .

Baker said NHS hospital services now faced a significant increase in demand impacting on both patients and staff. "We are now seeing record levels of attendances at emergency departments and this is affecting patients' experience of care and creating pressure on staff that cannot be sustained long term," he said.

NHS leaders praised frontline staff for their dedication while acknowledging there was more to do.

James Devine, director of the NHS Confederation's acute network, said, "We know that where problems have been identified, trust leaders will reflect on their individual scores and see what further improvements they can make."

CQC. Urgent and emergency care survey 2020. September 2021. www.cqc.org.uk/publications/surveys/urgent-emergency-care-survey-2020. 